\title{
METODOLOGIA DE APLICAÇÃO DO ESTUDO DAS SOFT-SKILLS NO ENSINO TÉCNICO À DISTÂNCIA
}

\author{
GOIÂNIA/GO JUNHO/2018
}

\author{
Leovir Cardoso Aleluia Júnior - UFG - leovir.engmecatronica@gmail.com \\ Paulo de Sá Filho - IfGoiano - prof.paulo@hotmail.com.br \\ Marco Antônio de Carvalho - IFGoiano - marco.carvalho@ifgoiano.edu.br \\ Fabíola de Luca Coimbra Bomtempo - CNI - fabiolabomtempo@gmail.com
}

Tipo: Relato de Experiência Inovadora (EI)

Categoria: Métodos e Tecnologias

Setor Educacional: EDUCAÇÃO MÉDIA E TECNOLÓGICA, EDUCAÇÃO CORPORATIVA, EDUCAÇÃO CONTINUADA EM GERAL

\begin{abstract}
RESUMO
Atualmente, o mercado de trabalho tem dado grande ênfase nas competências sócio comportamentais dos colaboradores, isso se justifica, à medida em que a competitividade e globalização avançam, tornando a gestão de pessoas, ou simplesmente o departamento de recursos humanos de uma empresa, uma peça central dentro de uma organização. Em matérias vinculadas em sites especializados, apontam que para $77 \%$ dos empregadores, as competências sócio comportamentais, doravante chamadas de Soft-Skills, são tão importantes quanto as competências técnicas, doravante chamadas de Hard-Skills. Dessa forma, justifica-se a implantação do estudo dessas competências nos ensinos básicos e técnicos. Esse trabalho tem por propósito justamente $o$ desenvolvimento de uma metodologia de ensino das Soft-Skills em cursos técnicos à distância no SENAI. Propôs-se uma abordagem inicialmente explicativa, utilizando de fóruns de discussão, tais fóruns, apesar de não pontuados, tiveram grande aceitação, e o assunto foi amplamente discutido. $A$ posteriori, utilizou-se dos encontros presenciais de determinadas unidades curriculares para trabalhar 0 assunto, em consonância com as expectativas do mercado de trabalho para os egressos do curso técnico em Automação Industrial. O projeto inicia-se no ambiente virtual de aprendizagem (AVA), permeia os momentos presenciais, porém, extrapola grandemente as paredes das salas de aula, uma vez que o aprendizado foi levado para seus respectivos postos de trabalho. Faz-se, no presente trabalho, além de toda a exposição do estudo de caso, o desenvolvimento metodológico, os resultados, conclusões e apontamentos para trabalhos futuros.
\end{abstract}

Palavras-chave: Soft-Skills, Ensino Técnico, Educação a Distância

\section{AGRADECIMENTOS}

AGRADECEMOS A DEUS POR NOS PRESENTIAR COM O DOM DA VIDA, A NOSSA FAMÍLIA PELO APOIO E AO SENAI POR NOS OPORTUNIZAR COM ESSA CAMPO TÃO FÉRTIL QUE É A EDUCAÇÃO PROFISSIONAL E TECNOLÓGICA. 


\section{INTRODUÇÃO}

Cotidianamente, em meio estudantil, pessoal, profissional, acadêmico, ou qualquer meio que envolva contato humano, pessoas são desafiadas a lidarem com situações que excedem o conhecimento técnico (ou Hard-Skills), mostrando a fragilidade das formações, básicas, técnicas e superiores, no que tange às competências sócio emocionais, comportamentais e pessoais. Essas, podem e devem ser compreendidas como pedras basilares no contexto organizacional, o que tem levado não apenas organizações, como também instituições de ensino, a pensarem na formação de seus egressos [1].

Tais premissas, devem levar a sociedade, especialmente os educadores, a encontrar formas concisas de trabalhar mais do que o conhecimento técnico-científico, mas primar também pelo desenvolvimento de competências que excedam o cobrado em provas de conclusão de cursos, vestibulares e concursos. Nesse contexto, a metodologia de ensino interacionista [2], recebe natural destaque, haja vista o precoce desenvolvimento do caráter de pró atividade, autodidatismo, além de primar pela centralização do processo de ensino aprendizagem no aluno, retirando do professor/tutor a tutela completa de tal processo.

Nota-se, a partir do exposto até aqui, que esse conceito, tão mencionado nos dias atuais, Soft-Skills, excede o caráter organizacional e atinge profundamente aspectos diversos na vida de um indivíduo, tanto em contexto individual como na sua gestão de emoções, quanto no seu envolvimento com outros indivíduos e com o meio no qual esteja incluso. Isso justifica a constante procura por "coachings executivos". Esse profissional, nesse contexto, atua como um facilitador, a fim de despertar dentro do indivíduo, competências que ele próprio desconhecia.

Aqui, não se implica tornar-se o tutor, professor ou mediador, um coaching, mas entender o que se espera do egresso de cursos diversos no que tange à suas competências que excedam as intelectuais.

A Educação à Distância [3] [4], já tão amplamente debatida e aceita na sociedade não apenas brasileira, tem ficado de fora do debate acerca da implantação de Soft-Skills, haja vista a própria ausência de artigos e estudos sobre a aplicação do tema no contexto EAD [5]. O que torna o presente trabalho, um marco inicial para tal discussão. 


\section{METODOLOGIA}

A metodologia de aplicação do estudo das Soft Skills no ensino técnico na modalidade $E A D$, baseou-se na utilização de fóruns de discussão não avaliativos e exposição do assunto nos encontros presenciais de determinadas unidades curriculares. A metodologia desenvolvida foi testada em uma turma de técnico em automação industrial, curso esse que é desenvolvido em 5 módulos (Básico, Introdutório, Específicos I, II e III).

No referido curso, as unidades curriculares do módulo básico são, em síntese, fundamentos, tanto elétricos, quanto mecânicos, razão pela qual não foram escolhidas para aplicação da metodologia. Dessa forma, optou-se por iniciar a aplicação em uma turma já do módulo Introdutório, mais especificamente, cursando a unidade curricular Acionamento de Dispositivos e Atuadores.

Diante do baixo nível de conhecimento acerca do assunto, inicia-se a abordagem a partir da exposição contextualizada do tema. Ressalta-se que, por tratar-se de um curso técnico à distância, lida-se, quase que exclusivamente com adultos, com perfil mostrado na tabela I.

\begin{tabular}{|l|l|l|}
\hline \multicolumn{2}{|l|}{ Perfil dos Estudantes - Téc. Automação Industrial - Modalidade EAD } \\
\hline SEXO & Homens & $100 \%$ \\
\hline IDADE & $20-25$ & $10 \%$ \\
\hline & $25-30$ & $15 \%$ \\
\hline & Acima dos 30 anos & $75 \%$ \\
\hline Ocupação & Empregado & $100 \%$ \\
\hline & Empregado Industriário & $92 \%$ \\
\hline & Empregado não Industriário & $8 \%$ \\
\hline
\end{tabular}

Tabela I - Perfil dos Estudantes: Fonte (próprios autores)

A partir dos dados mostrados na TABELA 01, nota-se claramente que o público é exclusivamente masculino, formado quase que em sua unanimidade por homens adultos. Sabe-se, que, pelos pilares da andragogia [6], o ensino de adultos dá-se inicialmente pelo conhecimento e aceitação da necessidade da posse dos conhecimentos que irá adquirir. $O$ adulto, em linhas gerais, precisa conhecer a necessidade daquele estudo [7]. Assim, o primeiro passo é explanar acerca do tema, utilizando para isso um fórum de discussão introdutório. Nesse fórum definiu-se o que seriam as Soft Skills, bem como suas diferenças das Hard Skills. Além disso, listou-se um conjunto de competências esperadas para os profissionais do século $\mathrm{XXI}$, assim 
como mostrou-se que o domínio de tais competências constitui um incrível diferencial competitivo.

Após a explanação inicial, seguiu-se com a abordagem individual de determinadas Soft Skills levantadas inicialmente no fórum de introdução ao tema, mediante interação com os discentes. Para tais abordagens individuais, utilizou-se também de fóruns de discussão (não avaliativos), cada um deles ilustrando o papel daquela determinada competência interpessoal utilizando situações problema, além de estudos de caso, vídeos explicativos, motivando o debate. Cada um dos fóruns (tanto o introdutório quanto os demais, tiveram durações aproximadas de uma semana).

Aliados aos estudos individuais das Soft-Skills por meio do ambiente virtual de aprendizagem, os estudantes foram também motivados a emprega-las nos encontros presenciais das unidades curriculares, Gestão da Manutenção e Implementação de Equipamentos e Dispositivos. Isso ocorreu, incentivando os professores dos momentos presenciais a, durante as aulas, utilizar metodologias ativas de aprendizagem.

Cita-se nesse contexto, o trabalho desenvolvido na Unidade Curricular de Gestão da Manutenção. Nessa, o professor presencial realizou a divisão da turma em equipes, solicitando a cada uma delas o desenvolvimento de um plano de manutenção para determinado equipamento ou instalação industrial. As equipes definiram os seus gerentes de manutenção, supervisores e técnicos. Após essas definições, utilizou-se da metodologia de sala de aula invertida [8] e [9]. O professor tornou-se exclusivamente um mediador, a medida que os grupos iam elaborando os planos de manutenção, e os gerentes e supervisores eram automaticamente impelidos à utilizar competências de liderança, escuta ativa, relacionamento eficaz com os colaboradores, entre outras. De mesmo modo, os técnicos também tinham de demonstrar competências interpessoais.

Todas as observações eram anotadas e posteriormente mencionadas pelo professor/mediador, haja vista, ser separado momento da aula para discussão entre as equipes, cada qual apresentando seus planos de manutenção desenvolvidos, explicando como se daria a rotina de manutenção, e as demais equipes realizavam intervenções.

Mediante o que foi listado, pode-se, resumir a metodologia da seguinte forma:

- Fórum de explicação e introdução ao tema;

- Fóruns específicos de cada competência relevante aos alunos;

- Aplicação das competências nos momentos presenciais de disciplinas 
selecionadas para tal;

- Análise dos resultados à distância e presenciais;

- Compilação dos resultados;

- Contínuo debate do tema através de fóruns, atividades, além dos encontros presenciais.

\section{RESULTADOS E DISCUSSÃO.}

Todos os fóruns de discussão sobre o tema foram fóruns não pontuados, desse modo, com a participação opcional (porém incentivado no AVA, grupo da turma no WhatsApp, e por e-mail), seria possível perceber o interesse real dos alunos sobre o tema. A tabela 02 mostra os índices de participação dos alunos nos dois primeiros fóruns. Ressalta-se que o percentual de participação, refere-se ao percentual dos alunos da turma que participaram do fórum e o percentual de nova participação, refere-se ao percentual de alunos que fizeram mais de uma interação no fórum.

\begin{tabular}{|l|l|l|}
\hline Índices de Participação nos fóruns \\
\hline Fórum & Percentual de participação & $\begin{array}{l}\text { Percentual de nova } \\
\text { participação no mesmo fórum: }\end{array}$ \\
\hline Introdutório & $68 \%$ & $95 \%$ \\
\hline $\begin{array}{l}\text { Específico - Soft-Skills de } 74 \% \\
\text { Liderança }\end{array}$ & $100 \%$ \\
\hline
\end{tabular}

Tabela II - participação dos alunos nos dois primeiros fóruns: Fonte (próprios autores)

Nota-se uma grande participação, especialmente, por se tratar de uma atividade não avaliativa. No fórum introdutório, alguns alunos, em suas contribuições, apontaram situações interessantes, onde numa entrevista de emprego, o recrutador deixa claro que buscava por uma pessoa com perfil bastante alinhado com Soft-Skills, uma vez que, segundo o recrutador, competências técnicas poderiam ser formadas. O depoimento do aluno é transcrito aqui.

\section{"Boa Tarde Pessoal,}

Bom, realmente esses itens citados acima pelo professor Leovir, são muito importantes, eu já conhecia todos, porém não por esse termo (soft-skills). 
Uma experiência que tive ao entrar aqui na usina, em 2006 foi que durante a minha entrevista, o supervisor da Elétrica na época, hoje falecido, um senhor muito bem conceituado e experiente me perguntou algumas coisas técnicas das quais algumas delas eu não soube responder, porém eu soube Ihe dar com a situação muito bem devido alguns itens acima como Comunicação Verbal, Positividade e Criatividade, com isso, a resposta dele foi, "Não se preocupe, precisamos de uma pessoa que saiba trabalhar em equipe, que tenha espírito de liderança, que seja proativo, que saiba falar em público, porque o resto (Parte Técnica) ele aprenderá com a gente, da nossa maneira." E foi assim, que "eu acredito" ter passado na entrevista. Tenho todas essas facilidades pois sempre trabalhei com todos os tipos de pessoas, das mais delicadas as mais brutas, e sempre consegui resultados positivos. E digo por experiência própria, muitas empresas hoje, se atentam mais para as (soft-skills) do que para as competências Técnicas, claro, tentam juntar as duas coisas mas, na hora da seleção, as (soft-skills) servirá muito bem como critério de decisão. Pense nisso! "

No fórum específico sobre as Soft-Skills da Liderança de Sucesso, os discentes puderam explanar sobre suas opiniões acerca de bons líderes e especialmente, sobre as competências notadas e não notadas em seus atuais líderes. Quase $50 \%$ das participações nesse fórum, apontavam para situações cotidianas em seus ambientes de trabalho, onde os líderes poderiam facilmente terem resolvido determinados conflitos se tivessem usado algumas das Soft-Skills mencionadas na descrição do fórum.

As tabelas III e IV mostram as avaliações dos estudantes após a aplicação da metodologia.

\begin{tabular}{|c|c|c|}
\hline \multicolumn{3}{|c|}{ Considerações apontadas pelos alunos na pesquisa de satisfação } \\
\hline & $\begin{array}{l}\text { Já conheciam o tema "Soft } \\
\text { Skill". }\end{array}$ & $\begin{array}{l}\text { Já conheciam o tema, mas } \\
\text { com outros nomes. }\end{array}$ \\
\hline \multirow[t]{2}{*}{ Percentual } & $10 \%$ & $48 \%$ \\
\hline & $\begin{array}{l}\text { Consideraram importante } \\
\text { trabalhar o conteúdo em EAD. }\end{array}$ & $\begin{array}{l}\text { Consideraram importante } \\
\text { trabalhar o conteúdo em } \\
\text { atividades presenciais. }\end{array}$ \\
\hline \multirow[t]{2}{*}{ Percentual } & $87 \%$ & $90 \%$ \\
\hline & $\begin{array}{l}\text { Consideraram importante } \\
\text { conhecer o tema e aprofundar } \\
\text { nesse conhecimento. }\end{array}$ & $\begin{array}{l}\text { Consideraram que } \\
\text { conhecimento das Soft } \\
\text { contribuirá para o seu } \\
\text { currículo profissional: }\end{array}$ \\
\hline
\end{tabular}


Percentual

$78 \%$

$95 \%$

Tabela III - Avaliação dos Discentes: Fonte (próprios autores)

De modo geral, as avaliações foram muito positivas, haja vista tanto o docente do momento presencial, quanto os alunos, avaliaram de forma muito positiva a aplicação do tema Soft Skill.

\begin{tabular}{|c|c|c|}
\hline \multicolumn{3}{|c|}{ Considerações apontadas pelos alunos na pesquisa de satisfação } \\
\hline & $\begin{array}{l}\text { Avaliaram que os fóruns forar } \\
\text { melhor aproveitado } \\
\text { debatendo o assunto. }\end{array}$ & $\begin{array}{l}\text { Avaliaram que a aula } \\
\text { spresencial foi mais produtiva } \\
\text { incluindo o assunto. }\end{array}$ \\
\hline \multirow[t]{2}{*}{ Percentual } & $66 \%$ & $75 \%$ \\
\hline & $\begin{array}{l}\text { Consideraram important } \\
\text { continuar a trabalhar } \\
\text { assunto no AVA. }\end{array}$ & $\begin{array}{l}\text { Consideraram } \\
\text { continuar a } \\
\text { conportante } \\
\text { conteúdo em abalhar } \\
\text { presenciais. }\end{array}$ \\
\hline Percentual & $87 \%$ & $90 \%$ \\
\hline
\end{tabular}

Tabela IV - Avaliação dos Discentes: Fonte (próprios autores)

\section{CONSIDERAÇÕES FINAIS}

É notória a necessidade de uma formação mais ampla dos profissionais, seja na área profissional ou em qualquer outra área do conhecimento. Essa formação deverá abandonar o modelo basilar centrado no desenvolvimento de Hard Skills, e primar por uma metodologia que forme o profissional, não apenas tecnicamente, como também em Soft Skills.

Existe uma grande lacuna no estudo de Soft Skills em toda a educação brasileira, isso é visto, especialmente, na educação à distância. Dessa forma, com os bons resultados obtidos mediante a aplicação dessa metodologia proposta e aplicada no presente artigo, pôde-se e pode-se encontrar resultados expressivos o desenvolvimento de capacidades sociais, pessoais e interpessoais nos estudantes da modalidade EAD, formado egressos alinhados às atribuições esperadas nos profissionais do século XXI. 
[1] - Mendes da Silva, Carlos Manoel. ESTUDO DAS COMPETÊNCIAS PESSOAIS E INTERPESSOAIS DE ACORDO COM AS SOFT SKILLS E HARD SKILLS NOS EMPRESÁRIOS DAS PMES - Instituto Superior de Línguas e Administração, dissertação. Vila Nova de Gaia, Portugal, 2012.

[2] - ALVES, Vanessa da Silva; SILVA, Elisana Ribeiro - A TEORIA SÓcIOINTERACIONISTA NO ENSINO DE MATEMÁTICA E FILOSOFIA - Revista Eletrônica de Educação de Alagoas (REDUC), Vol. 02, № 01, Maio de 2014.

[3] - ALVES, Lucineia. EDUCAÇÃO À DISTÂNCIA: CONCEITOS E HISTÓRIA NO BRASIL E NO MUNDO. Associação Brasileira de Educação à Distância, RBAAD, Vol. 10, 2011.

[4] MORAN, J. M. O que é Educação a Distância. Universidade de São Paulo. Disponível em: . Acesso em: 10 de março de 2018.

[5] PORTAL MINISTÉRIO DA EDUCAÇÃO. Legislação da Educação a Distância. Disponível em: . Acesso em: 30 jan. 2018.

[6] KNOWLES, M. S.; HOLTON, E. S. \& SWANSON, R. A. The Adult Learner. Butterworth-Heinemann, 2005.

[7]MERRIAM, S. B.; CAFFARELLA, R. S. \& BAUMGARTNER, L. M. Learning in Adulthood: a comprehensive guide. Jossey-Bass: John Wiley \& Sons, Inc., 2006.

[8] Sala de aula invertida: por que não reagem os pedagogos brasileiros ao neocolonialismo pedagógico? José Pacheco. Revista Educação. Disponível em: http://re vistaeducacao.com.br/textos/205/sala-deaula-invertidapor-que-nao-reagem-ospedagogosbrasileiros-311344-1.asp

[9] Flipped classroom: invertendo a maneira de ensinar. Revista TecEduc. Seção "Na frente". Disponível em: positivoteceduc.com.br/na-frente/flipped-classroominvertendo-amaneira-de-ensinar. 